\title{
A Comparative Study of the Multistage Solar Stills with Stacked Stages (MSS-SS)
}

\author{
Mfanafuthi Mthandeni Mkhize and Velaphi Msomi $(\mathbb{C}$ \\ Cape Peninsula University of Technology, Faculty of Engineering and the Built Environment, \\ Mechanical Engineering Department, P.O. Box 1906, Bellville 7535, South Africa
}

Correspondence should be addressed to Velaphi Msomi; msomiv@gmail.com

Received 16 August 2021; Revised 18 October 2021; Accepted 2 November 2021; Published 18 November 2021

Academic Editor: Yongping Chen

Copyright ( 92021 Mfanafuthi Mthandeni Mkhize and Velaphi Msomi. This is an open access article distributed under the Creative Commons Attribution License, which permits unrestricted use, distribution, and reproduction in any medium, provided the original work is properly cited.

\begin{abstract}
The current work conducts a comparative study of the waterbed multistage solar still with stacked stages (MSS-SS) and the vapourbased MSS-SS. Various experimental test results obtained from the vapour-based MSS-SS are briefly discussed in comparison with the waterbed MSS-SS reported in the literature. Based on the experimental observations and tests, the stage tray requires no maintenance and upper stages can operate even when the lower stages are nonoperational. About $0.8-41.3 \%$ distillate yield dropped from the upper stages when lower stages were exposed to the atmosphere. The upper stages increased their productivity by $7.1-15.4 \%$ when the lower stages were shut off completely. The waterbed-based MSS-SS preserves and reuses thermal energy much better even during off sunshine hours than the vapour-based system. The vapour-based MSS-SS is only productive during sunshine hours, and about $97-98 \%$ of the distillate is produced during daytime. Furthermore, the vapour based was able to produce $6.3 \mathrm{~kg} /$ day on average on the selected days.
\end{abstract}

\section{Introduction}

Small-scale thermal desalination devices have the advantage of being cheap, easy to construct, and being able to be a standalone system [1]. Rajamanickam and Ragupathy [2] reported that a solar still (water distiller) uses the process of evaporation and condensation to produce distilled water through solar thermal energy. During this process, impurities such as inorganic materials and chemicals are left behind in the pool of contaminated water in the basin. The study further reported that distillation is one of the earliest forms of water purification for mankind. These systems depend on solar radiation to produce freshwater [2, 3]. Furthermore, solar radiation availability depends on the geographical area where experimental tests are conducted [4]. However, solar thermal desalination stills have remained experimental devices as there is no large-scale operation system globally [5]. Therefore, Mkhize and Msomi [6] conducted a brief feasibility review study on the MSS-SS in southern Africa. The study reported that, based on the current regions experimenting on the thermal desalination devices and their solar radiation availability, there is an indication that southern Africa is capable of developing these systems as it receives enough solar radiation. Solar still can also be designed to be a hybrid system to increase their productivity [7]. Furthermore, there has been a need to increase the efficiency and productivity in the solar stills by including multieffect distillation in the solar stills [8].

There are two basic technologies used in desalting saline water (SW); they are thermal and membrane desalination [9]. Thermal desalination involves a phase change process where liquid changes to vapour (evaporation) and back to liquid (condensation). The membrane method is a singlephase process, and the liquid does not change phases [10]. However, renewable technologies as discussed earlier on are strongly dependent on the surrounding climate. The fluctuations and seasonal variation of the weather patterns result in the intermittent energy and freshwater output from renewable energy sources $[11,12]$. 
The MSS-SS that are multieffect systems have been reported to be more productive than the single effect solar stills. Schwarzer et al. [13] reported that single effect solar still produced $3-6 \mathrm{~L} / \mathrm{m}^{2} /$ day while the multieffect can produce $15-18 \mathrm{~L} / \mathrm{m}^{2} /$ day. They also have the ability to preheat the incoming SW and recover thermal energy released by vapour as a latent heat $[8,14]$. To further enhance the productivity of the MSS-SS systems, the evacuation process has been employed with pressure gradient such that $P_{1}>P_{2}>P_{3}>P_{4}$ and so on. That is, pressure in stage one, $P_{1}$, is greater than that of stage $2, P_{2}$, and stage two pressure is greater than that of stage $3, P_{3}$, and so on $[7,15]$. The evacuation process decreases the pressure in the stages below atmospheric pressure and as a result decreases the boiling point of (SW). Moreover, since the MSS-SS system has stacked stages, the direct heating as in the single effect solar still is not practical except for the uppermost stage [16]. Therefore, the MSS-SS are powered indirectly by solar collectors supplying thermal energy to the basin at the bottom of the condensing tower [15] or directly to the stages [17]. The MSS-SS supplied with thermal energy at the basin tend to have lower stages more productive during sunshine hours and upper stages during off sunshine hours [18, 19], while the direct thermal energy supply has different distillate yield pattern in the stages [17].

The current study, therefore, reports on the vapourbased MSS-SS results in comparison with waterbed-based MSS-SS. It compares the nature of the waterbed in the stages, the thermal energy supply into the condensing tower from the solar collectors and into the stages, the distillate yield patterns of the stages and the heat recovery, heat losses, and the effect of wind velocity reported on the MSS-SS.

\section{Description of the Waterbed and the Vapour- Based MSS-SS}

2.1. Waterbed-Based MSS-SS. A solar still in general is a device used to produce distilled water through thermal desalination. Solar stills have remained as small-scale desalination devices and are largely used for experimental purposes [5]. There is single and multieffect solar still used for small-scale production of distilled water. The multieffect solar still differs from the single effect solar still in that it consists of multiple effects in the desalination process [8]. The multieffect solar still is also able to preheat incoming SW and recover latent heat condensation $[8,13]$. In this study, however, attention is given to the multieffect solar stills. Within the multieffect solar stills, there are various configurations that exist $[7,13,15,17,18]$. Therefore, the scope was further narrowed to the MSS-SS. MSS-SS can be supplied with thermal energy either indirectly or by the combination of the direct and indirect thermal energy supply $[7,8,20]$. Figure 1 shows a simplified version of the condensing tower of the MSS-SS. Thermal energy supplied from the entry stage transfers its heat to stage 1 tray by means of the latent heat of condensation of the vapour. When SW in stage 1 is sufficiently heated and starts to evaporate, it transfers its heat to the following stage (stage 2). The sequential process of heat transfer repeats itself until the last stage of the assembly. Therefore, these stages can be said to be dependent on each other for thermal energy. Furthermore, the system produces the distillate from several stages, and the total cumulative distillate yield is the sum of all the distillate yield from each of the stages. Most of the MSS-SS have preheating and recovery built in the system to preserve thermal energy inside the system and reuse it. Some MSS-SS operate under vacuum pressure to enhance the productivity of the system $[7,15,17]$. The MSS-SS systems produce more distillate than single effect solar still [20].

2.2. Vapour-Based MSS-SS. The vapour-based is similar in many ways to the waterbed-based MSS-SS. The major differences are the absence of the waterbed and the way thermal energy is supplied to the stages. The vapour-based MSS-SS system is constructed in such a way that it has five compartments with passive basin solar still (BSS) integrated at the top of the system as shown in Figure 2. The integration of BSS to the system was meant to preheat seawater (SW) before it was transferred to the evaporator and also to allow desalination to also take place independently to the five stages. The number of stages was made to be five so as to increase the output of the system [20]. The seawater was transferred from the external tank to the BSS through the connection pipe (shown in Figure 2), and the level of seawater inside the BSS was controlled by a float valve. The SW moved from the BSS to the secondary tank through the zigzag copper pipes, and the use of copper material was to enhance heat exchange. The pipes were designed into a zigzag shape so that they can act as a cooling medium inside the compartment for condensation to take place. The flow and the level of water in the secondary tank were monitored and controlled by the second float valve.

The water was then transferred to the evaporator through the connecting pipe. The SW transferred from the secondary tank to the evaporator was heated up indirectly through the evacuated tube solar collector (ETSC). This then suggests that the evaporator had two openings at its base, that is, cold opening and hot opening. The cold opening was used to allow SW to flow from the evaporator to the ETSC for heating and then get back to the evaporator through the hot opening. The flow direction of SW was controlled by the installation of a one-way flow valve, and the flow of SW was initiated by the pressure difference and therefore no pump was involved. The highly heated SW entered the evaporator, where the vapour was then transferred to different compartments of the system through vapour make-up tubes. It is good to note that the transfer of vapour to different stages (compartments) of the system was not sequential like the water-bed-based system. This then suggests that the transfer of vapour to different stages occurred independently, which means the distillation process in each stage is independent of any other stages. This is advantageous in the sense that when one stage failed, the other stages could still continue to function. The vapour condensed at the stages due to the temperature difference that was caused by natural winds and the zig-zag tubes. The condensed vapour got collected through the U-shaped tubes installed at the lower end of 


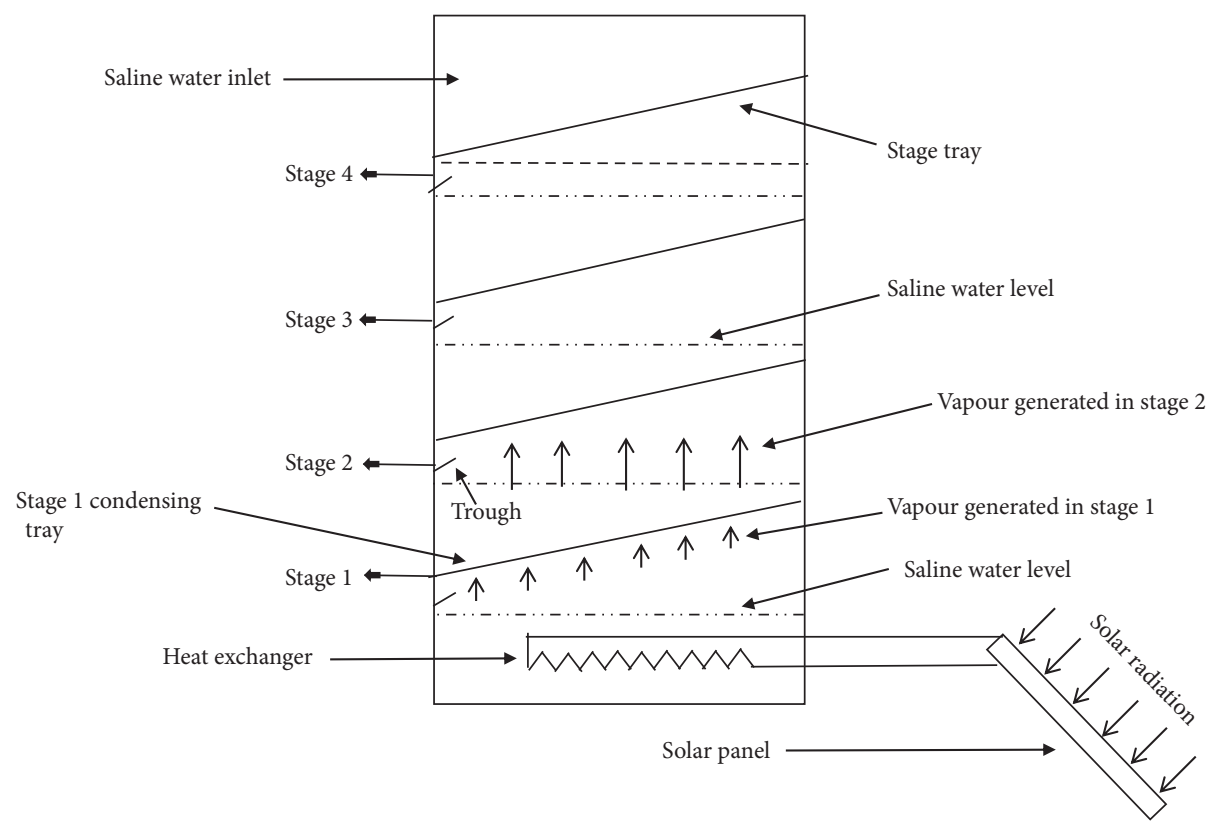

FIGURE 1: Waterbed-based MSS-SS.

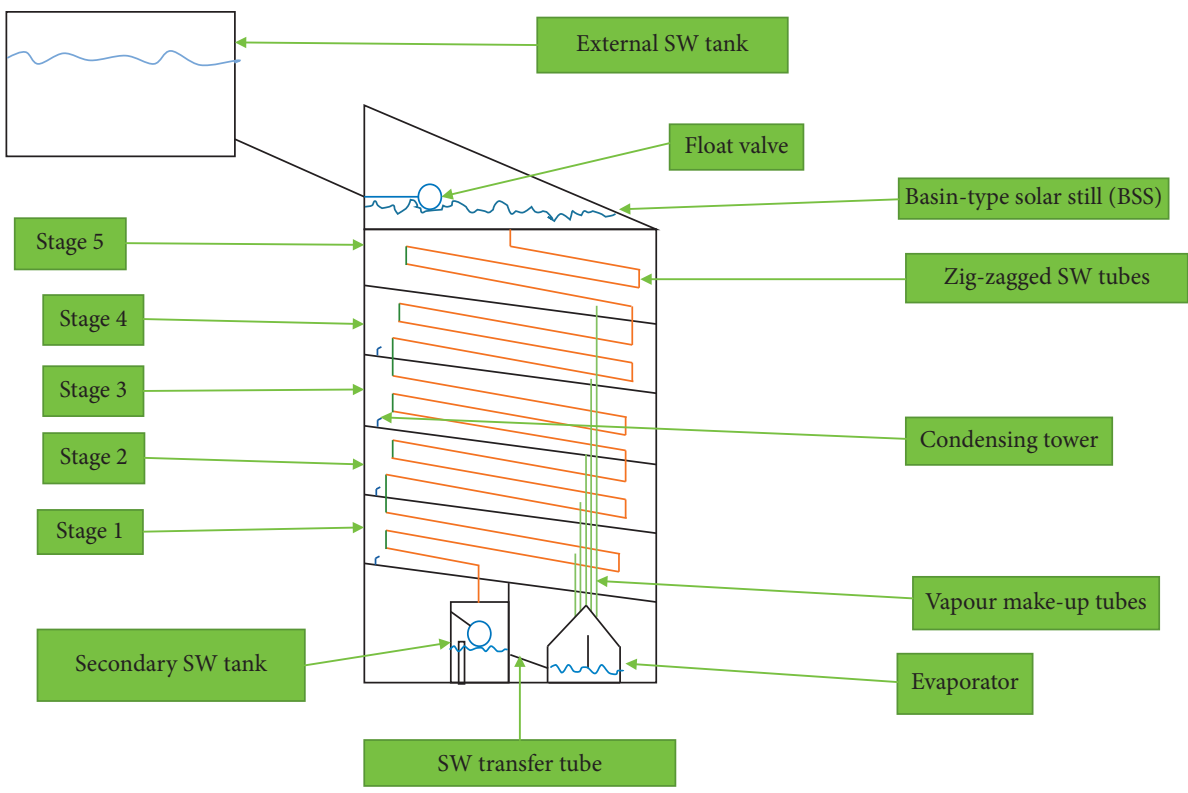

Figure 2: Vapour-based MSS-SS integrated with the BSS.

each stage. The U-shaped tubes were connected to the collection container where distillate was stored. It is good to note that this design is the first of its kind, and therefore there are a number of modifications that can be done in order to enhance the performance of this system.

\section{MSS-SS with Waterbed}

3.1. Nature and Effect of SW in the Stages of the Waterbed MSSSS. Waterbed in the MSS-SS can be described as an evaporative surface in a stage. It is the body of water that produces a vapour which can then be condensed and becomes liquid. Waterbed can be classified into two categories, namely, stagnant and flowing waterbeds. The stagnant waterbed is the pool of stationery SW on a stage tray that is heated and evaporated to produce vapour $[8,15,21]$. A flowing waterbed is the SW that is dynamic in nature, and it continuously flows over the surface of the stage tray while exchanging heat and releasing vapour in a stage $[17,18]$. The SW bed in the stages causes contamination over time due to salt residue, marine contaminants, or any other contaminants in the stages, which required cleaning of the stage trays and walls $[7,13]$. Cleaning of stages due to algae and scaling on the inner walls require removal of the trays [13] and disinfected with chemicals [7]. Firstly, the cleaning of stages increases maintenance costs [22]. Secondly, it increases the 
downtime of the plant as it is occasionally stopped for cleaning. Thirdly, the regular opening, cleaning, and replacement of stage trays may affect the vapour tightness and thus the productivity of the MSS-SS. In the MSS-SS, vapour tightness between the stages is important to avoid vapour leakages which would directly impact the productivity of the MSS-SS [7, 8].

Furthermore, SW is fed into the stages to recover heat from the latent heat of condensation and producing vapour. Depending on the total quantity of SW in the stages, the structure of the MSS-SS must be designed in such a way that it is able to withstand the total weight of the SW. For instance, Abdessemed et al. [23] report that each stage tray contained 6 litres of SW in the MSS-SS, while Shatat and Mahkamov [24] reported SW quantity in stage 1, stage 2, stage 3 , and stage 4 to be $18.4,4.2,4.8$, and 4.3 litres, respectively. Feilizadeh et al. [19] also reported that the SW quantities in the entry stage and each of the others were 20 and 14 litres, respectively. Thus, the construction of the structure and its cost may increase due to these requirements.

\subsection{Thermal Energy Supply and the Dependence of Stages in the} MSS-SS with Waterbed. The stagnant waterbed is largely heated up by the thermal energy supplied by solar collectors at the bottom of the condensing tower through an entry stage. This type of thermal energy supply setup leads to the upper stages relying on the lower stages to supply thermal energy through latent heat of condensation as it is sequential $[7,8,13,18,21]$. Therefore, the upper stages experience delays in starting up the desalination process [21]. The temperature gradient in this type of setup is such that lower stages maintain a higher temperature than the upper stages. Furthermore, lower stages become more productive due to increased thermal energy supplied. However, there is flexibility in the ways the thermal energy can be supplied in a flowing waterbed system [17]. In fact, Reddy et al. [17] reported that the upper stages maintained higher temperatures than the lower stages when heated SW is supplied directly to the stages from the solar collectors. Also, when the system is designed in such a way that there is both direct and indirect heating, the uppermost tray can start the desalination process due to direct heating by the sun $[7,20]$.

Schwarzer et al. [13] reported that the SW temperature in the entry stage was heated to a temperature of $95-100^{\circ} \mathrm{C}$. The SW temperature in the entry stage increased from morning and reached its maximum of $100^{\circ} \mathrm{C}$ around $14 \mathrm{~h} 00$ in the afternoon. During off sunshine hours, the SW in the entry stage was at $80^{\circ} \mathrm{C}$ and $45^{\circ} \mathrm{C}$ by the next morning. Franco and Saravia [18] also reported that the SW in the entry stage reached a temperature of $91^{\circ} \mathrm{C}$, which was higher than the rest of the other stages. It was reported by Abdessemed et al. [23] that the SW temperature in the entry stage in their study was $53.7^{\circ} \mathrm{C}$. These temperatures in the entry stage are of interest since they are the main source of thermal energy within the condensing tower. Furthermore, the temperature curves that the SW creates as solar radiation intensifies and fades away in the evening are important. For instance,
Abdessemed et al. [23] reported that the temperature of SW in the stages gradually increased and reached their maximum values later in the day. Shatat and Mahkamov [24] reported that, in their study, the SW temperature of the first and second tray ranged between 99 and $100^{\circ} \mathrm{C}$, while that of the last tray was $80^{\circ} \mathrm{C}$ when the system was partially insulated. However, due to the simulated nature of the study by Shatat and Mahkamov [24], the progression of the temperature curves throughout the day was based on the simulations.

3.3. Stage's Distillate Yield Pattern. In a system with a waterbed, the approach used to supply thermal energy into the system influences the distillate yield pattern of the stages. Firstly, the temperature gradient from the bottom stages to the uppermost stage is the same as all the waterbed-based MSS-SS. That is, lower stages maintain a high temperature while the upper stages maintain relatively low temperatures. The distillate yield pattern, therefore, follows the same pattern as the temperature gradient $[18,23]$. However, in the MSS-SS reported by Reddy et al. [17], where thermal energy was not supplied from the bottom, the upper stages maintain higher temperatures and thus higher productivity as well.

\subsection{Thermal Energy Recovered and Lost from the MSS-SS and} the Effect of Wind Velocity. In most of the MSS-SS discovered in the literature surveyed, the SW (feed water) was supplied from the top of the stacked stages. This feed water played two additional roles on top of replenishing SW in the system. The first role was to be preheated by the latent heat released by the vapour in the stages. Secondly, it recovered heat or cooled that vapour down to condense effectively [18]. However, in a system with a flowing waterbed, the feed water was supplied differently than those with a stagnant waterbed. Reddy et al. [17] reported that the SW water was supplied from the tank and into the solar collector and then the condensing tower. The heated SW then released its sensible and latent heat in a stage as it flowed over the trays' surface. As a result, the upper stages achieved and maintained higher temperature values than the lower stages. Also, Soni et al. [7] reported that the SW was fed directly into individual stages and not from the top of the stacked stages.

Karimi Estahbanati et al. [21] reported that, amongst other things, the removal of the distillate from the system constitutes thermal energy losses in the system. Franco and Saravia [18] reported that the SW that has not been evaporated in the stages reached the bottom tray at its highest temperature. Due to continuous incoming SW from the top of the stages, excessive hot SW was ejected from the bottom tray. In the study reported by Reddy et al. [17], the SW flowing over the surfaces of the stage trays was collected in the brine collecting tank outside of the condensing tower. However, it was not specifically reported as to whether this brine was reused or not, but it left the system with some thermal energy. Soni et al. [7] also reported the overflow where excessive SW was stored after being drained from the system. Thus, the above-reported setup constitutes thermal energy losses from the system. 
There have not been many reports on the direct effect of wind velocity in the waterbed-based MSS-SS. However, Reddy et al. [17] reported that decreasing wind velocity increased the distillate yield in the system. This was because of reduced heat losses from the solar collector and thus, increasing the thermal energy input into the system. This wind velocity was not reported to have a direct effect on the cooling tower but the solar collector.

\section{Comparative Results of the Vapour-Based MSS-SS versus Waterbed MSS-SS}

The development of vapour-based MSS-SS seeks to address problems that are faced by the waterbed-based normal MSSSS and some of those challenges are discussed in this section. Karimi Estahbanati et al. [21] reported that the low productivity of the upper stages was associated with the thermal energy supply at the bottom of the system. The upper stages totally depend on the lower stages for thermal energy supply. Low heat transfer efficiency between the stages was as a result of heat loss from the walls, vapour condensing on the walls and other parts/components where it cannot be collected, droplets dropping back into the pool of SW, removal of some thermal energy with freshwater, and device's operation in unsteady mode resulting in the storage of some energy at the end of the experiment. The current study may also add that removing the hot brine solution during operation also removes with it some of the thermal energy from the system.

4.1. Nature and Effect of SW in the Stages of the Vapour-Based MSS-SS. Even though the system had no waterbed in the stages, an experimental observation was conducted to ensure that the stages were uncontaminated over time. SW flowing the zig-zagged SW tube shown in Figure 2 can be classified as a flowing waterbed that is not in direct with the stage trays. The observations were conducted over a period of 2 months. A physical method was used for checking distillate yield quality and was subdivided into two, namely, electrical resistance and $\mathrm{pH}$ tests [25]. In terms of the electrical resistance, any significant decrease in the distillate electrical resistance would indicate increased contamination in the stages. This was the case since the distillate came into contact with the stage trays and walls. Table 1 shows the electrical resistance of some results obtained during the tests conducted on random days over a period of 2 months. Each stage distillate was tested separately to register any variations, if any, since very pure water increases its electrical resistance due to the low presence of dissolved solids. The low electrical resistance values indicated the presence of large metallic elements in water [26]. The SW and tap water electrical resistance were tested, and their values were fixed at $14.2 \times 10^{3} \Omega$ and $128.6 \times 10^{3} \Omega$, respectively. Comparing the SW resistance value, it was much lower than any of those in Table 1. The data in Table 1 also show that, in most cases, stages 3 and stage 4 had higher electrical resistance compared to other stages.

The accepted guidelines for $\mathrm{pH}$ levels of drinking water fit for human consumption range from 6.5 to 8.5. Moreover, the $\mathrm{pH}$ levels are affected by the changing water temperatures (WHO, 2007). According to DWAF (1996), the high aluminum concentration causes chronic human health effects and may increase the acid levels in water. Table 2 shows the $\mathrm{pH}$ results and the corresponding distillate temperatures tested over two days. The results show an increase in acid levels in the distillate by registering lower $\mathrm{pH}$ levels which may be a direct result of the use of aluminum materials for the construction of the condensing tower.

For stage trays and walls, the only method that could be used was the physical observations by inspecting the stages. For a period of 10 months and after elaborate observations through inspections, the stage trays remain uncontaminated with any algae or scaling. This was due to the apparent reason that no corrosive SW was directly in contact with the stage trays and walls. Figures 3(a) and 3(b) show the stage trays and stage wall on February 9, 2021, when it was opened for inspection. The whitish color on the tray and wall was due to the vapour condensing on the surfaces and the heating and cooling of the trays. Other than those, no contamination was observed. Based on the experimental tests and observations conducted, no cleaning of stages is required for the stages of the vapour-based MSS-SS.

Furthermore, the vapour condensing on the walls and other parts/components of the waterbed-based MSS-SS ends up dropping back to the pool of SW due to the fact that the design does not allow it to be collected. However, since the vapourbased MSS-SS had not waterbed in the stages, all the condensate whether condensed on the wall or trays was collected. There was no distillate dropping in the pool of SW and thus cannot be collected. Minimizing the SW in the entire system also reduces the structural strength required, and it further makes the condensing tower easy to handle and move from one location to another without having to drain the SW in it.

However, the heat losses through the stage were an inherent challenge as it does to other MSS-SS. In fact, due to the minimal SW flowing through the stages in a zig-zagged SW tube, the outside wind had to be used to enhance the cooling of the stages. When the system was fully insulated, it reached the thermal damage condition [24].

The vapour-based was designed and constructed to have minimal SW in the system. The total amount of SW in the entire condensing tower was estimated to be 9.6 litres, including that of the evaporator and the secondary SW tank. Therefore, the structure could be moved and lifted without draining SW in the system. Furthermore, the frame structure of the system was constructed with light material as no heavy SW was present in the system. It also meant that the construction cost of the structure was low as no reinforcements were required to withstand heavy loads [22].

\subsection{Thermal Energy Supply and the Dependence of Stages in the} MSS-SS with Waterbed. In the vapour-based MSS-SS, thermal energy was supplied in the entry stage from the ETSC and into the evaporator shown in Figure 2. The differences were the quantity of SW in the entry stage at any time compared to the waterbed-based MSS-SS, the nature of the waterbed, and the way in which thermal energy was 
TABLe 1: Distillate electrical resistance results per stage of the MSS-SS.

\begin{tabular}{|c|c|c|c|c|c|c|c|}
\hline Date & Av. sol. irradiance $\left(\mathrm{W} / \mathrm{m}^{2}\right)$ & \multicolumn{6}{|c|}{ Ohms $(\Omega)\left(\times 10^{3}\right)$} \\
\hline May 26,21 & 208.3 & 78.7 & 82.9 & 649 & 194.3 & 64.3 & 115.5 \\
\hline May14, 21 & 269.6 & 98.6 & 154.8 & 847 & 969 & 173.2 & 908 \\
\hline Mar 26, 21 & 301.4 & 33.8 & 65.5 & 132.7 & 469 & 81.2 & 111.9 \\
\hline May 01,21 & 338.8 & 80.3 & 688 & 186.1 & 950 & 106.1 & 687 \\
\hline Apr 30, 21 & 340.2 & 99.8 & 178.1 & 982 & 1160 & 139.3 & 838 \\
\hline Mar 04,21 & 377.9 & 36.1 & 45.4 & 91.7 & 392 & 57.4 & 56.6 \\
\hline Apr 16, 21 & 386.6 & 76.1 & 73.0 & 109.7 & 472 & 71.2 & 69.5 \\
\hline Mar 21, 21 & 404.6 & 65.3 & 72.3 & 434 & 705 & 74.6 & 132.9 \\
\hline Apr 01, 21 & 411.1 & 76.6 & 88.6 & 191.3 & 587 & 94.9 & 151.2 \\
\hline & Average & 76.2 & 175.4 & 441.5 & 688.3 & 100.6 & 376.8 \\
\hline
\end{tabular}

TABle 2: Distillate $\mathrm{pH}$ results per stage of the MSS-SS.

\begin{tabular}{lccccc}
\hline \multirow{2}{*}{ Description } & \multicolumn{2}{c}{ May 04, 2021 } & \multicolumn{2}{c}{ May 05, 2021 } & pH mean value \\
& pH level & Temp. $\left({ }^{\circ} \mathrm{C}\right)$ & pH level & Temp. $\left({ }^{\circ} \mathrm{C}\right)$ & 21.0 \\
BSS & 6.33 & 21.4 & 5.39 & 20.8 & 5.86 \\
Stage 5 & 6.75 & 21.7 & 4.87 & 21.0 & 6.81 \\
Stage 4 & 7.84 & 22.2 & 5.11 & 21.2 & 6.48 \\
Stage 3 & 7.87 & 22.1 & 5.67 & 21.0 & 6.84 \\
Stage 2 & 7.76 & 22.6 & 5.91 & 21.6 & 6.33 \\
Stage 1 & 6.67 & 22.1 & 5.99 & 22.0 & 7.06 \\
Tap water & 7.19 & 22.0 & 6.93 & 22.2 & 8 \\
SW & 7.90 & 22.2 & 8.10 & & \\
\hline
\end{tabular}

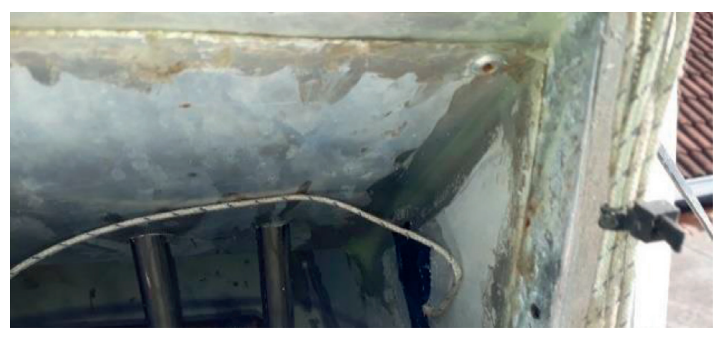

(a)

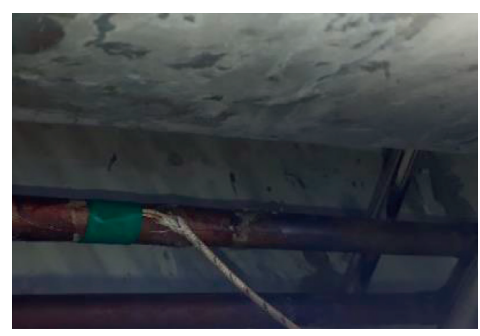

(b)

Figure 3: (a) Stage tray; (b) stage wall.

supplied to the stacked stages. Therefore, unlike the waterbed-based MSS-SS, the quantity of SW heated by the series-connected ETSCs at a time was approximately $0.5 \mathrm{~kg}$. It was reported by Ahsan et al. [27], Franco and Saravia [18], and Chen et al. [20] that enhanced distillate yield was achieved at minimum SW levels. Also, it was reported in the literature that the temperature behavior of a larger body of SW in the entry stage is such that it increased gradually and reached its maximum later in the day, corresponding to the maximum solar radiation on the day. However, a different temperature behavior for a minimal quantity of SW was experienced. Figure 4 shows the temperature curve of the SW in the evaporator under varying solar intensities for the spring and summer seasons. The MSS-SS was experimentally tested under actual weather conditions. As it can be seen from Figure 4, there is a sharp increase in the SW temperature in the morning.

The curves also differ under the summer season (high solar intensity and longer sunshine hours) and spring season (moderate solar intensify and shorter sunshine hours). At the beginning of spring, the curves start to sharply increase between 09 h00 and 10 h00 am, while in summer, the curves start to increase as early as $07 \mathrm{~h} 30 \mathrm{am}$. However, regardless of available solar intensities on different days, the SW temperature was mostly maximum around $95^{\circ} \mathrm{C}$. Later in the afternoon, the curves show a sharp decrease in temperature under low solar intensities and shortened sunshine hours. As the summer days approach, the curves start to decrease gradually into the night, which indicates continued desalination into the night. The higher temperature during daytime hours means enhanced evaporation in the evaporator. In comparison with the waterbed MSS-SS, the vapour-based MSS-SS is more productive for a longer duration of time during daytime as it maintains elevated temperature.

However, the biggest advantage of the waterbed-based MSS-SS is that the SW in the entry stage and the rest of the stages maintains higher temperatures even after off sunshine hours. Therefore, it can continue with the desalination 


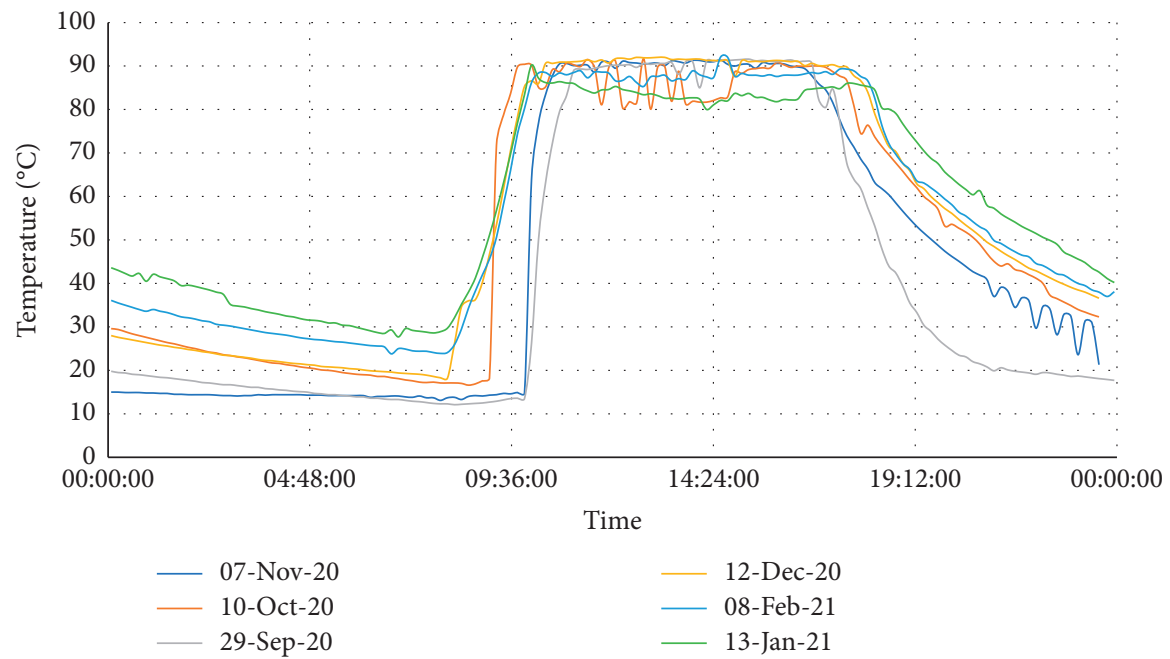

FIgURE 4: Evaporator SW temperature versus time.

process for longer during the night. Furthermore, due to minimal SW in the entry stage and the rest of the system, the temperature had dropped below $30^{\circ} \mathrm{C}$ by morning as shown in Figure 4. This is not the case in a waterbed-based MSS-SS as the temperature of $45^{\circ} \mathrm{C}$ and above is possible [13]. Also, the vapour-based is extremely reliant and sensitive to fluctuating solar intensities. For instance, on October 10, 2020 , and January 13,2021, there was a sudden drop in the temperature curves somewhere during sunshine hours. These drops are directly linked to the fluctuating solar intensities due to cloud cover and other meteorological factors. Therefore, the vapour-based MSS-SS is much more suitable for uniform thermal energy supplies with no interruptions. The fluctuating solar radiation is not ideal as an energy supplier to the system.

Figure 5 shows solar irradiance collected for the corresponding days to those in Figure 3. The highest collected daily solar irradiance on average was on January 13, 2021, at $584.98 \mathrm{~W} / \mathrm{m}^{2}$, while the lowest collected solar irradiance was on September 29, 2020, at $385.7 \mathrm{~W} / \mathrm{m}^{2}$. Despite these two higher and lower limits of solar thermal energy, the SW temperature in the entry stage did not increase more as a result of increased thermal energy input. Thus, there is a limit to which the SW can increase its temperature to its maximum. That is, the SW temperature increase is proportional to the thermal energy input until it reaches a certain value, and thereafter no effects on the SW temperature. Satyamurty [28] reported that when the surface reaches its maximum thermal energy-absorbing limits, it would not increase its temperature any further. Instead, at its maximum limit, it starts to lose an equal amount of incoming heat. It is believed that the same phenomenon occurred in the ETSC due to the minimum quantity of SW that no longer transfers that heat somewhere else due to the circulation in the ETSC manifold.

In the MSS-SS with a waterbed, the vapour from the entry stage must first heat the stage tray of stage 1, the tray heats up the SW water, and the SW produces the vapour to heat up the tray of stage 2. A similar concept was applied to the vapour-based MSS-SS in the vapour make-up tubes. The vapour must heat the tube until both the vapour and the tube achieve thermal equilibrium before the vapour can be delivered to the stages since the thermal energy is supplied by the vapour directly to the stages and no transferring of latent heat between the stages. The stages of the vapour-based MSS-SS can be said to be independent. The independence of the stage was aimed at establishing the extent to which the vapour-based MSS-SS stages can be affected by the loss of heat in the lower stages. The independence of these stages was experimentally observed from the spring season of 2020 to the winter of 2021 (September 2020 to June 2021). To test the independence of stages, two approaches were used. Firstly, the lower stages (stage 1 and stage 2) were simultaneously and alternately exposed to the atmosphere by opening them. Secondly, the vapour make-tubes supplying the vapour to these stages were plugged off simultaneously and alternately. During these tests, no distillate was produced from these two stages.

The results from these exposure experimental observations show that the combination of low solar intensity and high wind velocity has detrimental effects on the yield of the upper stages. The results further show that during days with low solar intensities and high wind velocities. The vapour make-up tubes supplying vapour to the upper stages and passing through these stages (stage 1 and stage 2) would cool down considerably, thereby reducing the amount of vapour reaching the stages. However, during high solar intensity and low wind velocities, the effect of exposing the lower stages to the atmosphere was negligible. The overall results show that the daily distillate yield from the upper stages was reduced by $5.8-41.3 \%$ under low solar intensity and high wind velocity. During days with high solar intensity, such as in summer, a slight daily distillate yield decreased from 0.8 to $2.4 \%$. Wind velocity did not have significant effects on cooling the vapour make-up tubes.

When the second experimental observation was made, no atmospheric exposure was allowed. That is, all stages were sealed and isolated from the outside elements and influences. 


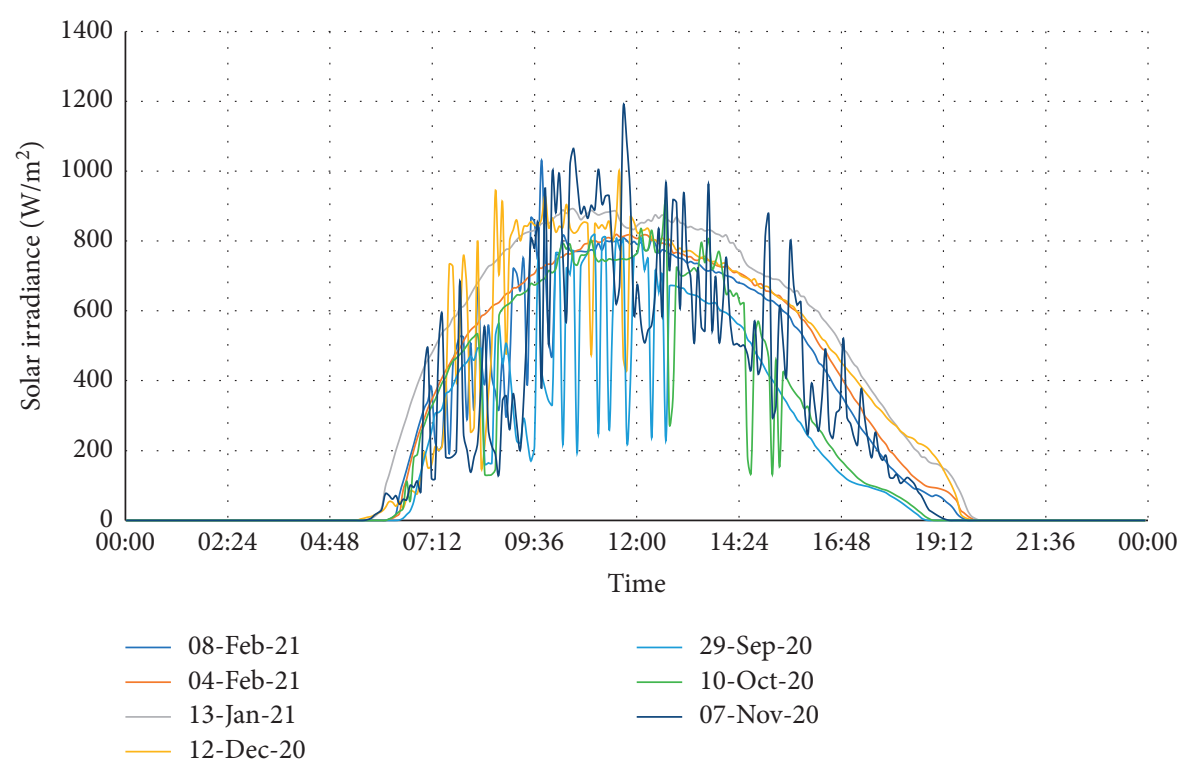

FIGURE 5: Solar irradiance versus time.

Stage 1 and stage 2 vapour-make-up tubes were plugged off or shut off, preventing any vapour supply to these stages. The results from this test show that there is no productivity loss in the upper stages due to the shutting down of the lower stages. In fact, about $7.1-15.4 \%$ increase in the daily cumulative distillate yield was observed. The most significant distillate yield increase was observed in stage 5 .

These two experimental observations sought to address the scenario of vapour leak and or vapour losses in the lower stages and observed the productivity of the upper stages. In the literature, it was reported that the upper stages depend on the lower stages for thermal energy. Therefore, should any thermal energy loss occur in these lower stages, the waterbed-based MSS-SS would be greatly affected. The experimental observation conducted on the vapour-based MSS-SS was to learn the extent to which the upper stages depend on the lower stages under this system.

4.3. Stage's Distillate Yield Pattern. It has been reported in the literature with the exception of Reddy et al. [17] that the temperature gradient in the stages of the waterbed-based MSS-SS is higher for lower stages and low for upper stages. Figure 6 shows the temperature gradient of the stages under different operating conditions. In the vapour-based MSS-SS, the temperature gradient fairly follows the same path. However, the temperature gradient tends to change slightly with different operating conditions. For instance, on October 10, 2020 (spring season), the system was fully insulated, and the temperatures of the stages were higher as shown in Figure 6. But they still follow the same profile as other stages on other days. On November 07, 2020, the system was completely uninsulated, and thus, the temperature gradient changed altogether as shown in Figure 6. During the summer season, the system was completely uninsulated throughout as the temperature difference between the condensing and evaporative (the evaporator) surfaces decreased. In fact, under very high solar intensities, the condensing surfaces' temperature would exceed that of the evaporative surface and that caused a condition known as thermal damage [24]. On January 13, 2021, stage $1 \mathrm{SW}$ temperature can be seen to exceed the temperature of the evaporative surface. However, stage 4 can be seen to always be higher than those of stage 2 and stage 3 . Therefore, the temperature gradient of the vapour-based MSS-SS does not exactly follow that of the waterbed-based MSS-SS.

Furthermore, the distillate yield pattern is totally different from those reported from the waterbed-based MSSSS. Figure 7 shows that the stages with relatively low SW temperatures yield more distillate, while with those that maintain high SW, temperatures are less productive. Once again, with the exception of Reddy et al. [17], lower stages were reported to be more productive in the waterbed-based MSS-SS. However, due to a different approach to supplying thermal energy, Reddy et al. [17] reported that the upper stages were more productive. The distillate yield pattern of the vapour-based MSS-SS follows neither of these yield patterns reported in the literature. Furthermore, as it was established under Subsection 4.2 that when 1 or 2 vapour make-up tubes were plugged off, the vapour was redirected to other stages. It can be reasonably assumed that stage that maintains higher SW temperature was unable to effectively condense the vapour. The uncondensed vapour in the stages would block or prevent any additional incoming vapour from the evaporator. The vapour from the evaporator was then redirected to cooler stages such as stage 3 and stage 5 . Hence, stage 3 and stage 5 proved to be more productive than others. Occasionally, distillate yield from stage 2 would rival that of stage 3 , depending on prevailing solar intensities. Also, on November 07, 2020, both Figures 6 and 7 show that when the SW temperature in the stages is not preheated, it means inadequate vapour was supplied to the stages. Therefore, the distillate yield remained lower on this day. 


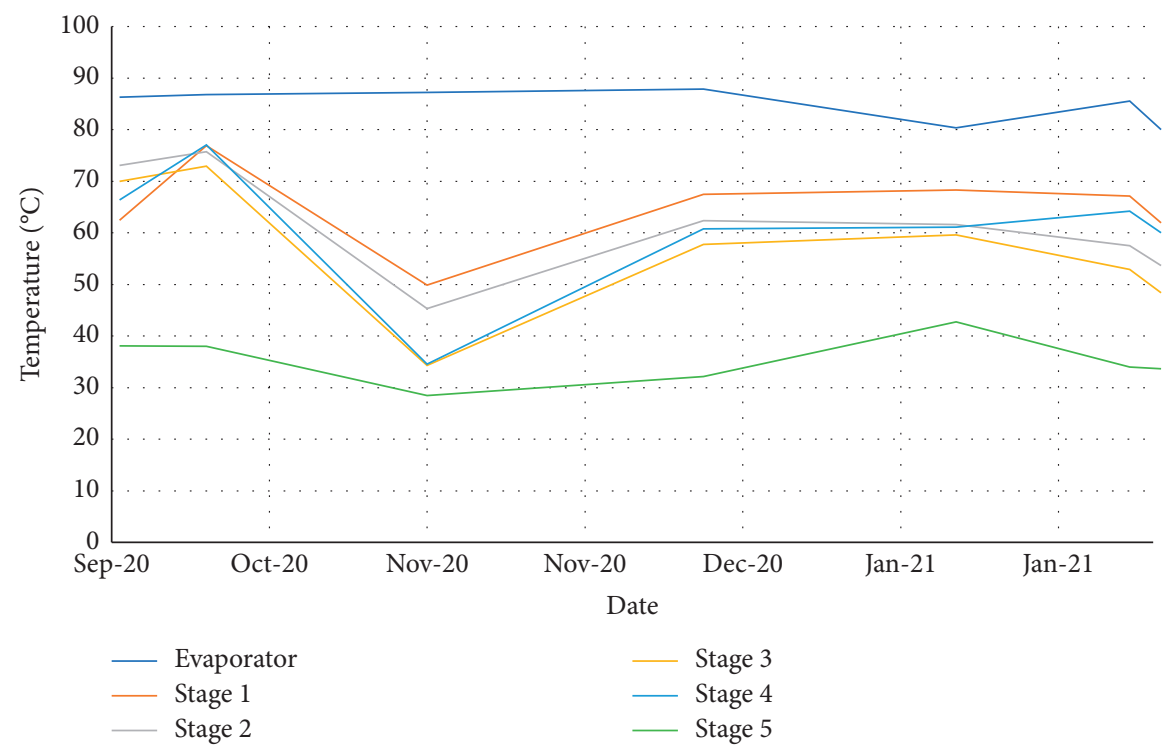

FIGURE 6: SW temperature versus stage numbers.

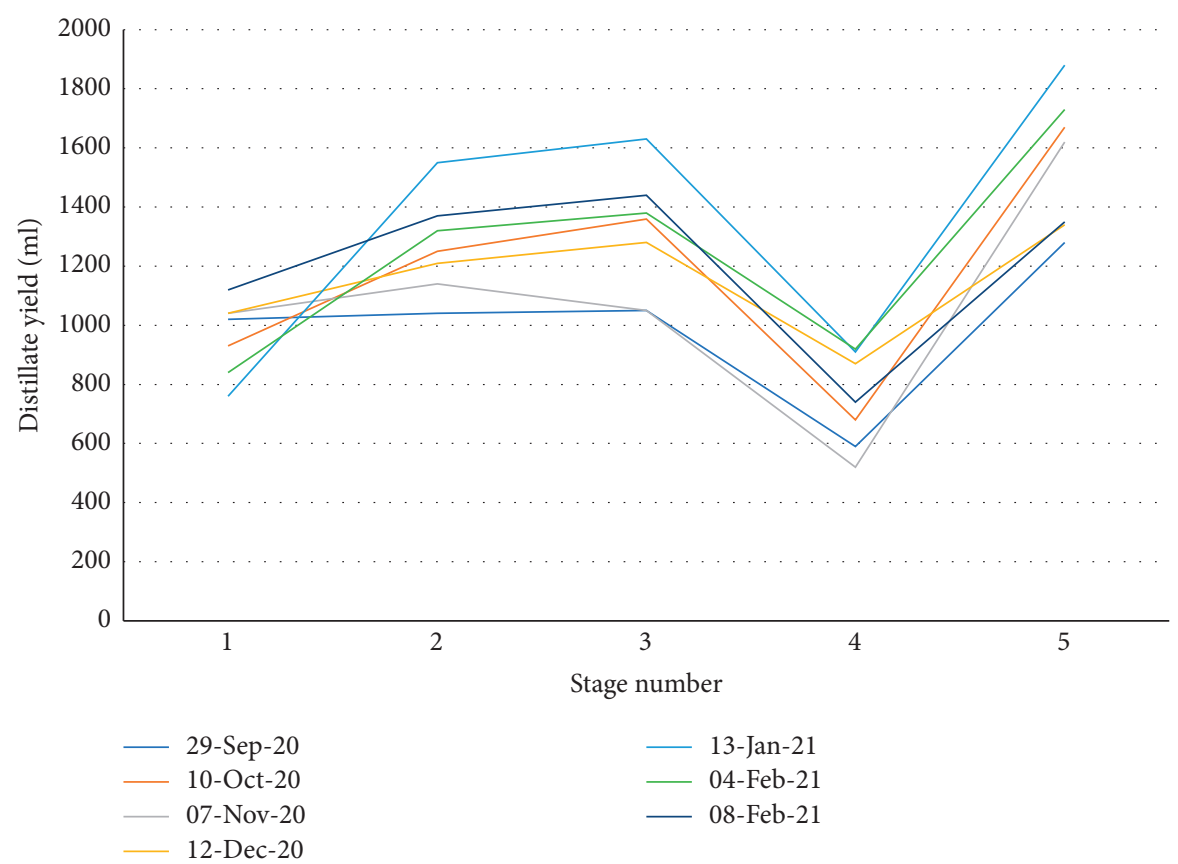

Figure 7: Distillate yield pattern versus stage numbers.

4.4. Thermal Energy Recovered and Lost from the MSS-SS and the Effect of Wind Velocity. In a vapour-based MSS-SS, the SW was supplied from the top as reported in the waterbed-based MSS-SS. The difference was that the SW was confined in a zigzagged SW tube and thus not in contact with the stage trays. The SW was preheated as it flowed down the stages. The latent heat of condensation was recovered from the vapour and thereby cooling the vapour down. Figure 6 shows the preheating of SW and heat recovery from the vapour. For instance, the preheating was most effective when the vapour-based MSS-SS was fully insulated. On October 10, 2020, stage 1-stage 5 SW temperatures were $73.5,72.5,69.2,74.4$, and $36.7^{\circ} \mathrm{C}$, respectively. The stage walls and stage tray temperatures were 67.7 and $70.9^{\circ} \mathrm{C}$, respectively, while on September 29, without any insulation, the preheated SW temperatures were 64.2, 67.4, 65.3, 63.8, and $37.9^{\circ} \mathrm{C}$, respectively. The stage walls and trays were 64.5 and $62.5^{\circ} \mathrm{C}$, respectively. On October 10,2020 , for instance, the insulation on the body of the system was able to preserve some thermal energy and thus effectively preheating the SW. The challenge with this, however, was the narrowing temperature difference between the evaporator operating at $85.7^{\circ} \mathrm{C}$ and the condensing surfaces. On September 29, 2020, without any insulation, the SW and condensing surface's temperatures were lower compared to those on October 10, 2020. This then 
suggests that increased thermal energy was lost when no thermal insulation was used on the body. Meanwhile, using the insulation increased condensing surfaces temperature.

The experimental results suggest two possibilities for the vapour-based MSS-SS. The first one is that there is a limiting thermal energy value for the system to operate without reaching thermal damage. This could be the case since there is minimal SW in the evaporator. The second one is that the quantity of cooling SW in the stages needs to be increased to cope with the amount of heat delivered by the vapour in the stages. However, other than the experimental results reported by Shatat and Mahkamov [24] using flood lights, no other waterbed-based system reported excessive condensing surfaces temperatures. It was also observed in the vapourbased-MSS-SS that the wind velocity had a huge impact in cooling the stage walls. The effect of the wind was more apparent when the system was uninsulated and the walls were exposed to the passing winds. Based on Figure 4, the SW temperature in the evaporator reaches roughly the same temperature during the day. Therefore, regardless of the solar intensity on these two days, the condensing surfaces were much cooler without thermal insulation.

Due to the small quantity of SW in the stages to cool the vapour while being preheated, the preheated temperatures remained relatively low in the secondary tank as reported in Figure 2. Since the preheated SW was to replace the evaporated water in the evaporator, the SW flow rate was according to the amount of evaporated SW in the evaporator. Therefore, Table 3 shows the resultant preheated SW temperature in the secondary tank for the days presented in Figure 4. The quantity of preheating SW from the zig-zagged SW tube was insufficient to adequately increase the temperature of SW in the secondary tank.

In an attempt to minimize heat losses from the system, the brine solution was recirculated and removed over a certain period of time. For instance, under-summer conditions with high solar intensities, the brine solution was removed (flushed out) from the system once a week. The flushing out was dependent on the electrical resistance value of the brine solution, which indicated the increase in salinity levels. Abdenacer and Nafila [29] reported that the salt content in the SW is about 35 grams per litre $(\mathrm{g} / \mathrm{l})$ while that of the brackish water with a high concentration is $10 \mathrm{~g} / \mathrm{l}$ and beyond. Al-Shammiri [30] reported that increasing the salinity in the saline water increases the boiling point of water. Also, the evaporation rate of water with a salinity level of $26 \mathrm{ppm}$ varies from 2000 to $6000 \mathrm{~g} / \mathrm{h} \mathrm{m}^{2}$, while that of water with a salinity level of $68720 \mathrm{ppm}$ varies from 500 to $1700 \mathrm{~g} /$ $\mathrm{h} \mathrm{m}^{2}$. Therefore, when the SW electrical resistance values reached about 3 times the original value $\left(14.2 \times 10^{3} \Omega\right)$, the SW was flushed out. Under moderate solar intensities, these
TABLE 3: Secondary SW tank temperatures.

\begin{tabular}{lc}
\hline Date & Sec. tank SW temp. $\left({ }^{\circ} \mathrm{C}\right)$ \\
\hline Sept. 29, 2020 & 32.3 \\
Oct. 10, 2020 & 42.4 \\
Nov. 07, 2020 & 32.5 \\
Dec. 12, 2020 & 45.5 \\
Jan. 13, 2021 & 54.1 \\
Feb. 04, 2021 & 40.5 \\
Feb. 08, 2021 & 42.2 \\
\hline
\end{tabular}

electrical resistance values could be reached in more than 2 weeks. Furthermore, the brine solution was only flushed out in the morning before the first solar incidence was recorded. This was to avoid removing any thermal energy from the system interrupting the desalination process. The mornings were preferred due to the fact that the SW temperature had already dropped to room temperature by the morning; see Figure 4.

\section{Comparative Distillate Yield for MSS-SS and Other Various Systems}

The comparative results from the vapour-based and the waterbed-based MSS-SS are being discussed in this section. Table 4 shows the summary of different waterbed-based MSS-SS systems and the current system (vapour-based MSSSS system). The distillate yield of systems included in Table 4 is the maximum output of each system at clear sky conditions. The current system produced a maximum of $6.3 \mathrm{~kg} /$ day (excluding BSS), while other systems produced less and more than the current system. There are some factors that seem to be influential on the performance of each system. This includes the solar collector size and type, the number of stages, the stage angles, and the tray area. A typical example can be seen when comparing the current system's performance with those that have solar collectors that are more than the current system $[13,17]$. The distillate yield of these systems is 2 times or 3 times more than the distillate of the current system. However, the performance of the current system is not bad compared to the waterbed-based MSS-SS system. This then suggests that the current system is promising and can be optimized for enhanced performance.

\section{Economic Analysis of the MSS-SS}

The economic analysis of the MSS-SS was carried out based on the methods reported in the literature [19, 21-24]. The equations guiding the cost estimation of the vapour-based MSS-SS are as follows: 
TABLe 4: Distillate yield summary.

\begin{tabular}{|c|c|c|c|c|c|c|c|}
\hline \multirow[b]{2}{*}{$\begin{array}{l}\text { Bottom tray area } \\
\left(\mathrm{m}^{2}\right)\end{array}$} & \multicolumn{3}{|c|}{ System sizes } & \multirow[b]{2}{*}{$\begin{array}{l}\text { Tray } \\
\text { angle } \\
\text { (deg.) }\end{array}$} & \multirow[b]{2}{*}{$\begin{array}{c}\text { Number of } \\
\text { stages }\end{array}$} & \multirow[t]{2}{*}{ Distillate yield } & \multirow[t]{2}{*}{ Author } \\
\hline & $\begin{array}{l}\text { Upper trays } \\
\left(\mathrm{m}^{2}\right)\end{array}$ & Stage height $(\mathrm{mm})$ & $\begin{array}{l}\text { Solar collector } \\
\text { area }\left(\mathrm{m}^{2}\right)\end{array}$ & & & & \\
\hline $0.4 \times 0.4$ & & $\begin{array}{l}140 \text { (from SW } \\
\text { surface) }\end{array}$ & $\begin{array}{l}5 \text { for FPSC and } \\
2.2 \text { for ETSC }\end{array}$ & $5-16$ & $5-7$ & $15-18 \mathrm{~L} / \mathrm{m}^{2} /$ day & $\begin{array}{c}\text { Schwarzer et al. } \\
\text { [13] }\end{array}$ \\
\hline $0.4 \times 0.47$ & 1 & N/A & N/A & 25 & 4 & $1.010 \mathrm{~kg} / \mathrm{hr}$ & $\begin{array}{l}\text { Franco and } \\
\text { Saravia [18] }\end{array}$ \\
\hline N/A & 1 & 100 & $2 \times(1.35)$ & 16 & 4 & $\begin{array}{l}28.044 \mathrm{~kg} / \\
\mathrm{m}^{2} \text { day }\end{array}$ & Reddy et al. [17] \\
\hline N/A & N/A & $260-360$ & N/A & $\mathrm{N} / \mathrm{A}$ & 3 & $14.2 / \mathrm{m}^{2} /$ day & Ahmed et al. [31] \\
\hline $1.2 \times 0.4$ & $1.2 \times 0.4$ & $\begin{array}{l}160 \text { for the } 1 \text { st and } \\
125 \text { for the rest }\end{array}$ & N/A & 8 & 4 & $9 \mathrm{~kg} /$ day & $\begin{array}{c}\text { Shatat and } \\
\text { Mahkamov [24] }\end{array}$ \\
\hline $0.7 \times 0.7$ & $0.7 \times 0.7$ & 50 & $2.16 \times 1.07$ & 15 & 5 & $7.41 \mathrm{~kg} / \mathrm{m}^{2} /$ day & Singh et al. [32] \\
\hline 0.47 & 0.47 & N/A & N/A & 8 & 4 & $27.1 \mathrm{~kg} /$ day & $\begin{array}{c}\text { Karimi } \\
\text { Estahbanati [21] }\end{array}$ \\
\hline N/A & N/A & N/A & N/A & $\mathrm{N} / \mathrm{A}$ & 4 & $1370 \mathrm{ml} /$ day & $\begin{array}{c}\text { Abdessemed et al } \\
\text { [23] }\end{array}$ \\
\hline $0.4 \times 0.55$ & $0.4 \times 0.55$ & $\begin{array}{l}45 \text { (from SW } \\
\text { surface) }\end{array}$ & 0.9 & N/A & 3 & $7.29 \mathrm{~kg} /$ day & Chen et al. [20] \\
\hline $0.6 \times 0.4-1.2 \times 0.4$ & N/A & N/A & $\mathrm{N} / \mathrm{A}$ & $\mathrm{N} / \mathrm{A}$ & 4 & $8.88 \mathrm{~kg} /$ day & $\begin{array}{l}\text { Bait and Si-Ameur } \\
{[33]}\end{array}$ \\
\hline 0.47 & 0.47 & N/A & N/A & 8 & 4 & $9.54 \mathrm{~kg} /$ day & $\begin{array}{c}\text { Feilizadeh et al. } \\
{[19]}\end{array}$ \\
\hline Evaporator & 0.18 & $110-230$ & 1.8 & 8 & 5 & $6.3 \mathrm{~kg} / \mathrm{day}$ & $\begin{array}{l}\text { Vapour-based } \\
\text { MSS-SS }\end{array}$ \\
\hline
\end{tabular}

$$
\begin{aligned}
\mathrm{CRF} & =\frac{i(1+i)^{n}}{\left[(1+i)^{n}-1\right]}, \\
\mathrm{FAC} & =P \times \mathrm{CRF}, \\
\mathrm{SFF} & =\frac{i}{\left[(1+i)^{n}-1\right]}, \\
S & =0.2 P, \\
\mathrm{ASV} & =\mathrm{SFF} \times S, \\
\mathrm{AMC} & =0.15 \times \mathrm{FAC}, \\
\mathrm{AC} & =\mathrm{FAC}+\mathrm{AMC}-\mathrm{ASV}, \\
\mathrm{CPL} & =\frac{\mathrm{AC}}{M},
\end{aligned}
$$

where CFR is capital recovery factor, FAC is the fixed annual cost, $P$ is the present capital cost, SFF is the sinking fund factor, $S$ is a salvage value, ASV is an annual salvage value, AMC is an annual maintenance cost, AC is an annual cost, $\mathrm{CPL}$ is a cost per litre, $M$ is the average annual productivity, $i$ is an annual interest, and $n$ is the number of productive years of the system. The above equations were incorporated to excel for the computation of various factors. For the purpose of analysis, 260 clear sky days were assumed. The bank's lending interest rate, $i$, was estimated at $15 \%$ for funding. The system's estimated life expectancy in a number of years, $n$, was assumed to be 12 years.
When considering all the days when the system was producing the distillate at full capacity, the daily cumulative distillate yield was $7790 \mathrm{ml}$ (7.79 litres) and $6730 \mathrm{ml}(6.73$ litres) for the MSS-SS plus the BSS and the MSS-SS stages alone, respectively. The capital cost for the vapour-based MSS-SS was estimated to be R19 000 (all included). The CPL for the MSS-SS stages alone was found to be R2.23/litre. Meanwhile, the CPL for the MSS-SS plus the BSS combined was found to be R1.93/litre. Therefore, producing distilled water from the MSS-SS stages alone was more expensive when compared to the MSS-SS plus the BSS, and these costs were less than those of the municipality [34].

\section{Conclusion}

The study discussed the operational capabilities of the two types of the MSS-SS. It has been established that the vapourbased MSS-SS is more productive during sunshine hours and produces about $97-98 \%$ of its distillate during the day. Furthermore, it tends to lose an excessive amount of thermal energy due to inadequate cooling in the system. When insulated under high solar intensities, it reaches thermal damage and the desalination process stops altogether. The waterbed-based MSS-SS has the advantage of preserving thermal energy for much longer than the vapour-based MSS-SS. Also, it can recover the latent heat of condensation much more effectively and reuse it. It has also been established in the vapour-based MSS-SS that the upper stages can operate to some extent when the lower stages are nonoperational. It also presents a possibility of no maintenance in 
the stages, and thus, the vapour tightness would not be affected. The maximum output of the vapour-based MSS-SS was found to be 7.93 litres per day during a clear sky, and this output was found to be higher than some of the waterbedbased MSS-SS systems. It was also observed that the condensation mostly depends on the wind speed, and therefore it is anticipated that the incorporation of the cooling system can enhance the distillate yield. The cost analysis also reveals that the cost per litre is much lower than the cost of municipality litre.

\section{Data Availability}

The data used in producing this paper are available on request.

\section{Conflicts of Interest}

The authors declare that they have no conflicts of interest.

\section{Acknowledgments}

The authors would like to acknowledge the National Research Foundation for financial support.

\section{References}

[1] K. R. Ranjan and S. C. Kaushik, "Energy, exergy and thermoeconomic analysis of solar distillation systems: a review," Renewable and Sustainable Energy Reviews, vol. 27, pp. 709723, 2013.

[2] M. R. Rajamanickam and A. Ragupathy, "Influence of water depth on internal heat and mass transfer in a double slope solar still," Energy Procedia, vol. 14, pp. 1701-1708, 2012.

[3] S. Kumar and A. Tiwari, "Design, fabrication and performance of a hybrid photovoltaic/thermal (PV/T) active solar still," Energy Conversion and Management, vol. 51, no. 6, pp. 1219-1229, 2010.

[4] A. A. Al-Tabbakhand and A. A. Mohammed, "Experimental investigation of an evacuated tube solar air collector," Advances in Natural and Applied Sciences, vol. 11, no. 11, pp. 62-71, 2017.

[5] I. Goldie, R. D. Sanderson, J. D. Seconna, B. A. Delcarme, L. M. Daries, and L. A. Lodewyk, "A guidebook on household water supply for rural areas with saline groundwater," Water Research Commission, pp. 36-54, 2004.

[6] M. M. Mkhize and V. Msomi, "Feasibility of a multistage solar still in southern Africa," in Proceedings of the 2020 9th International Conference on Renewable Energy Research and Application (ICRERA), pp. 48-54, IEEE, Glasgow, Scotland, 2020.

[7] A. Soni, J. A. Stagner, and D. S.-K. Ting, "Adaptable wind/ solar powered hybrid system for household wastewater treatment," Sustainable Energy Technologies and Assessments, vol. 24, pp. 8-18, 2017.

[8] R. S. Adhikari, A. Kumar, and G. D. Sootha, "Simulation studies on a multi-stage stacked tray solar still," Solar Energy, vol. 54, no. 5, pp. 317-325, 1995.

[9] M. A. Eltawil, Z. Zhengming, and L. Yuan, "A review of renewable energy technologies integrated with desalination systems," Renewable and Sustainable Energy Reviews, vol. 13, no. 9, pp. 2245-2262, 2009.
[10] H. N. Panchal and S. Patel, "An extensive review on different design and climatic parameters to increase distillate output of solar still," Renewable and Sustainable Energy Reviews, vol. 69, pp. 750-758, 2017.

[11] P. Asmus, "Intermittency solutions: making intermittent renewable sources work for California... and the USA," Refocus, vol. 6, no. 2, pp. 36-38, 2005.

[12] C. Fant, C. Adam Schlosser, and K. Strzepek, “The impact of climate change on wind and solar resources in southern Africa," Applied Energy, vol. 161, pp. 556-564, 2016.

[13] K. Schwarzer, E. V. da Silva, B. Hoffschmidt, and T. Schwarzer, "A new solar desalination system with heat recovery for decentralised drinking water production," Desalination, vol. 248, no. 1-3, pp. 204-211, 2009.

[14] Z.-h. Liu, R.-L. Hu, and X.-j. Chen, "A novel integrated solar desalination system with multi-stage evaporation/heat recovery processes," Renewable Energy, vol. 64, pp. 26-33, 2014.

[15] B. A. Jubran, M. I. Ahmed, A. F. Ismail, and Y. A. Abakar, "Numerical modelling of a multi-stage solar still," Energy Conversion and Management, vol. 41, no. 11, pp. 1107-1121, 2000.

[16] Z. Haddad, A. Chaker, and A. Rahmani, "Improving the basin type solar still performances using a vertical rotating wick," Desalination, vol. 418, pp. 71-78, 2017.

[17] K. S. Reddy, K. R. Kumar, T. S. O’Donovan, and T. K. Mallick, "Performance analysis of an evacuated multi-stage solar water desalination system," Desalination, vol. 288, pp. 80-92, 2012.

[18] J. Franco and L. Saravia, "A new design for a passive atmospheric multistage still," Renewable Energy, vol. 4, no. 1, pp. 119-122, 1994.

[19] M. Feilizadeh, M. R. Karimi Estahbanati, A. S. Ardekani, S. M. E. Zakeri, and K. Jafarpur, "Effects of amount and mode of input energy on the performance of a multi-stage solar still: an experimental study," Desalination, vol. 375, pp. 108-115, 2015.

[20] Z. Chen, J. Peng, G. Chen et al., "Analysis of heat and mass transferring mechanism of multi-stage stacked-tray solar seawater desalination still and experimental research on its performance," Solar Energy, vol. 142, pp. 278-287, 2017.

[21] M. R. Karimi Estahbanati, M. Feilizadeh, K. Jafarpur, M. Feilizadeh, and M. R. Rahimpour, "Experimental investigation of a multi-effect active solar still: the effect of the number of stages," Applied Energy, vol. 137, pp. 46-55, 2015.

[22] E. El-Bialy, S. M. Shalaby, A. E. Kabeel, and A. M. Fathy, "Cost analysis for several solar desalination systems," Desalination, vol. 384, pp. 12-30, 2016.

[23] A. Abdessemed, C. Bougriou, D. Guerraiche, and R. Abachi, "Effects of tray shape of a multi-stage solar still coupled to a parabolic concentrating solar collector in Algeria," Renewable Energy, vol. 132, pp. 1134-1140, 2019.

[24] M. I. M. Shatat and K. Mahkamov, "Determination of rational design parameters of a multi-stage solar water desalination still using transient mathematical modelling," Renewable Energy, vol. 35, no. 1, pp. 52-61, 2010.

[25] J. J. Simonis and A. Nweze, "A novel approach for providing potable water in rural Sodwana Bay, northern Kwazulu-Natal, South Africa," Journal of Water, Sanitation and Hygiene for Development, vol. 6, no. 3, pp. 425-434, 2016.

[26] T. S. Light, S. Licht, A. C. Bevilacqua, and K. R. Morash, "The fundamental conductivity and resistivity of water," Electrochemical and Solid State Letters, vol. 8, no. 1, p. E16, 2004.

[27] A. Ahsan, M. Imteaz, U. A. Thomas, M. Azmi, A. Rahman, and N. N. Nik Daud, "Parameters affecting the performance of 
a low cost solar still," Applied Energy, vol. 114, pp. 924-930, 2014.

[28] V. V. Satyamurty, Solar Collector Basics, Module 9, 2021, Lecture 9, https://youtu.be/jilXDUxyPEs.

[29] P. K. Abdenacer and S. Nafila, "Impact of temperature difference (water-solar collector) on solar-still global efficiency," Desalination, vol. 209, no. 1-3, pp. 298-305, 2007.

[30] M. Al-Shammiri, "Evaporation rate as a function of water salinity," Desalination, vol. 150, no. 2, pp. 189-203, 2002.

[31] M. I. Ahmed, M. Hrairi, and A. F. Ismail, "On the characteristics of multistage evacuated solar distillation," Renewable Energy, vol. 34, no. 6, pp. 1471-1478, 2009.

[32] P. Singh, P. Singh, J. Singh, R. I. Singh, and K. Kundu, "March. Performance evaluation of low inertia multi-stage solar still," in Proceedings of the International Multi Conference of Engineers and Computer Scientists, pp. 14-16, Hong Kong, China, 2012.

[33] O. Bait and M. Si-Ameur, "Numerical investigation of a multistage solar still under Batna climatic conditions: effect of radiation term on mass and heat energy balances," Energy, vol. 98, pp. 308-323, 2016.

[34] South Africa. D. W. S., 2018, National Water and Sanitation Master Plan, 1, https://www.dws.gov.za/National\%20Water\% 20and\%20Sanitation\%20Master\%20Plan/Documents/ NWSMP(Master\%20Plan)\%20Call\%20to\%20Action\%20v10. 1.pdf. 